\title{
Poly (N-Trihydroxyl Alkane Substituted Pyrrole) Film Coated Electrodes for Catalytic Hydrogenation
}

\author{
Nobuhiro TAKANO*, Ryo IZUMI and Noboru TAKENO
}

Received April 25, 1996 ; Accepted May 20, 1996

\section{INTRODUCTION}

Incorporation of catalytic metals in conductive polymer films on electrode can be conveniently achieved and the application as an electrochemical catalysis electrode is expected ${ }^{1}$. We have previously reported the palladium incorporated poly [ $N$-(5-hydroxypentyl substituted pyrrole)] film electrode (P5HPy) ${ }^{2}$. However, this film electrode was not fully satisfied in catalytic function. Furthermore the construction of excellent and stable film electrodes is necessary. In particular, it is important to secure space for the movement of substrates in polymer film. We synthesized the $\mathrm{N}$-alkane substituted pyrrole monomers 1a and $\mathbf{1 b}$, which are linked a bulky molecular at a carbon chain terminal. In this paper, we report the preparation and properties of new poly ( $N$-trihydroxyl alkane substituted pyrrole) film electrodes $\mathbf{2 a}$ and $\mathbf{2 b}$ for electrocatalytic hydrogenation.

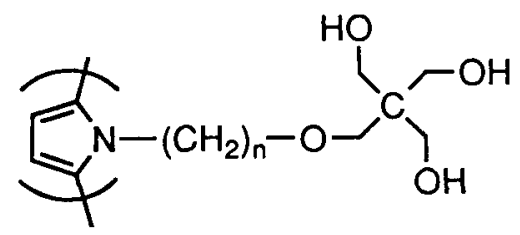

2a: $n=2$

$2 b: n=5$

Department of Applied Chemistry, Muroran Institute of Technology (27-1 Mizumoto-cho, Muroran 050, Japan)

Key Words : Trihydroxyl Alkane Substituted Pyrrole, Electro-Incorporation, Palladium, Polymer Catalytic Electrode

\section{EXPERIMENTAL}

As shown in Scheme 1 the trihydroxyl alkane substituted pyrrole monomers $1 \mathrm{a}$ and $\mathbf{1 b}$ were synthesized by ordinary method ${ }^{3}$. The monomers were purified by column chromatography using $\mathrm{AcOEt} / \mathrm{n}$-hexane as the eluent.

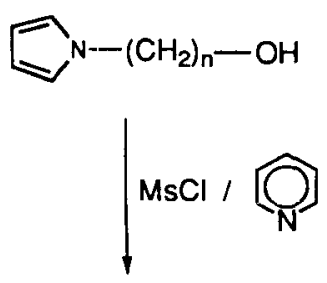<smiles>COCCCn1cccc1</smiles><smiles>OCC(CO)(CO)CO</smiles><smiles>[13CH3][13CH3]</smiles>

$1 a: n=2$

$1 b: n=5$

\section{Scheme 1}

NMR and IR spectroscopic data of the monomers followed; 1a : ${ }^{1} \mathrm{H}$ NMR $(270 \mathrm{MHz}$, $\left.\mathrm{DMSO}_{6}\right) \quad \delta \quad 3.31 \sim 3.35\left(\mathrm{~m}, 8 \mathrm{H}\right.$, $\left.\equiv \mathrm{C}-\mathrm{CH}_{2}-\mathrm{O}\right)$, 3.56 (t, 2H, J=5.6, 5.3, >N-CH $-\mathrm{CH}_{2}-\mathrm{O}$ ) , 3.99 (h, 2H, J=5.6, 5.3, >N-CH $-\mathrm{CH}_{2}-\mathrm{O}$ ) , 4.16 -4.19 (m, 3H, OH), 5.96 (t, 2H, J=2.0, 2.3, $\mathrm{PyH}_{3,4}$ ), 6.74 (t, 2H, $J=2.0,2.3, \mathrm{PyH}_{2.5}$ ); IR (neat) $v$ $3379,2929,2883,1500,1462,1437,1358$, 1286, 1122, 1090, 1041, 731, $619 \mathrm{~cm}^{-1} .1 \mathrm{~b}:{ }^{1} \mathrm{H}$ NMR (DMSO- $\left.d_{6}\right) \quad \delta \quad 1.23 \sim 1.26\left(\mathrm{~m}, 2 \mathrm{H},-\mathrm{CH}_{2}^{-}\right)$, 
$1.46 \sim 1.51\left(\mathrm{~m}, 2 \mathrm{H},-\mathrm{CH}_{2}-\right), 1.65 \sim 1.71(\mathrm{~m}, 2 \mathrm{H}$, $\left.\mathrm{CH}_{2}-\right), 3.30$ (t, $2 \mathrm{H}, J=6.6,>\mathrm{N}-\left[\mathrm{CH}_{2}\right]_{4}-\mathrm{CH}_{2}-\mathrm{O}$ ), $3.35 \sim 3.37\left(\mathrm{~m}, 8 \mathrm{H}, \equiv \mathrm{C}-\mathrm{CH}_{2}-\mathrm{O}\right), 3.84(\mathrm{t} 2 \mathrm{H}$, $\left.J=6.9,7.3,>\mathrm{N}-\mathrm{CH}_{2}-\left[\mathrm{CH}_{2}\right]_{4}-\mathrm{C}\right), 4.15-4.19(\mathrm{~m}$, $3 \mathrm{H}, \mathrm{OH}$ ), 5.95 (t, $\left.2 \mathrm{H}, J=2.0,2.3, \mathrm{PyH}_{3,4}\right), 6.71$ (t, 2H, J=2.0, 2.3, $\mathrm{PyH}_{2,5}$ ); IIR (neat) v 3378, $2937,2870,1500,1463,1438,1373,1282$, $1117,1092,1043,727,619 \mathrm{~cm}^{-1}$.

The formation of films $2 a$ and $2 b$ by electropolymerization on a glassy carbon electrode, the electro-incorporation of palladium, and the evaluation of catalytic activities for the film electrodes were carried out in a similar manner to our previous paper ${ }^{2}$.

\section{RESULTS AND DISCUSSION}

Figure 1 shows cyclic voltammograms observed during repetitive potential scans between 0 and $1.1 \mathrm{~V}$ vs. SCE in an electrolytic medium, $0.1 \mathrm{M}\left(\mathrm{mol} \mathrm{dm}^{-3}\right) \mathrm{Bu}_{4} \mathrm{NBF}_{4}$-acetonitrile containing $10 \mathrm{mM}$ monomers $1 \mathrm{a}$ and $\mathbf{1 b}$. Repetitive cycling leads to an intensification of the redox peaks, indicating that electrochemical polymerization of the monomers takes place on a glassy carbon disk electrode (Diameter $=3 \mathrm{~mm}$, Surface area $=0.071$ $\mathrm{cm}^{2}$ ). The resulting films $2 \mathbf{a}$ and $2 \mathbf{b}$ adhered strongly to the glassy carbon disk electrode surface. The redox peak height of 1 a was lower compared with those of $\mathbf{1 b}$. This behavior can probably be accounted for by assuming that the rate of the polymerization at 2 and 5 position of pyrrole ring was suppressed by the steric hindrance of trihydroxyl alkane having short carbon chain.

The incorporation of palladium in the film electrodes $\mathbf{2 a}$ and $\mathbf{2 b}$, which were prepared by the controlled-potential electrolysis ( $1.30 \mathrm{~V}$ vs. SCE), was performed by the immersion of the films in an aq. $50 \mathrm{mM} \mathrm{Na} \mathrm{NaCl}_{4}$ solution and the following electroreduction $(-0.3 \mathrm{~V})$ of permeated $\mathrm{PdCl}_{4}{ }^{2-}$ ion in the films. The amount of incorporated palladium $\left(W_{\mathrm{Pd}_{\mathrm{d}}}\right)$ was calculated on the basis of electricity passed during the two electron reduction of $\mathrm{PdCl}_{4}{ }^{2-}$ to $\mathrm{Pd}^{0}$. The amount of incorporated palladium in $\mathbf{2 a}$ and $\mathbf{2 b}$, which were formed under the polymerization electricity $Q_{f}=0.14 \mathrm{C} \mathrm{cm}^{-2}$, were 5.5 and $8.5 \mu \mathrm{g} \mathrm{cm}^{-2}$, respectively. The quantity of palladium in $2 \mathrm{a}$ was much less than those in $\mathbf{2 b}$. This fact suggests that the permeation of $\mathrm{PdCl}_{4}{ }^{2-}$ in matrix is reduced by a smaller space of $2 a$. The amount of incorporated palladium in $\mathbf{2 b}$ having five carbon chain was less than those of P5HPy $\left(Q_{f}=0.14 \mathrm{C}\right.$ $\left.\mathrm{cm}^{-2}, \mathrm{~W}_{\mathrm{Pd}}=9.3 \mu \mathrm{g} \mathrm{cm}^{-2}\right)^{2}$.

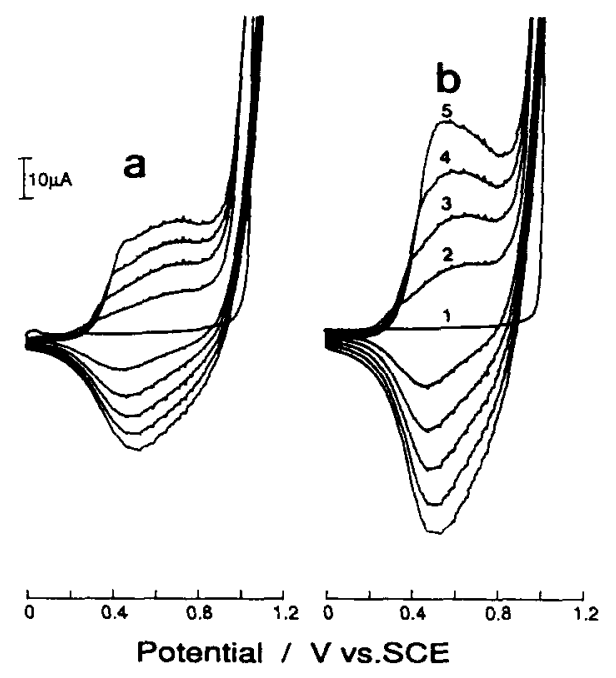

Fig. 1 Cyclic voltammograms of $1 \mathrm{a}$ (a) and $\mathbf{1 b}$ (b) in an acetonitrile containing $0.1 \mathrm{M} \mathrm{Bu}_{4} \mathrm{NBF}_{4}$ on a glassy carbon disk electrode. Monomer concentration: $10 \mathrm{mM}$. Scan rate: $100 \mathrm{mV} \mathrm{s}^{-1}$.

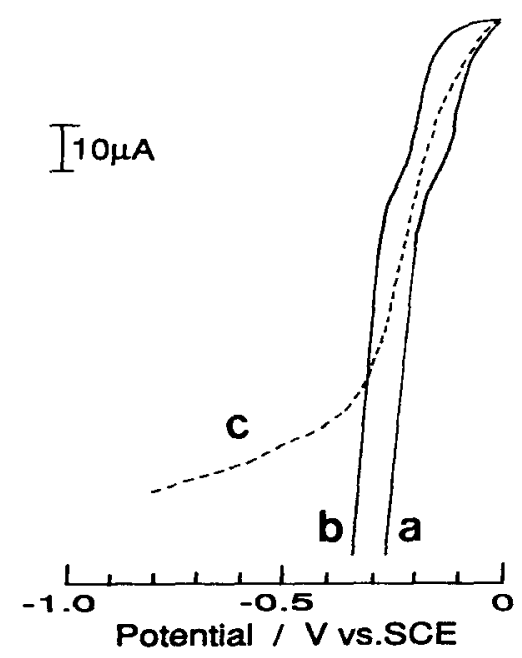

Fig. 2 Cathodic current-potential curves for the hydrogen evolution reaction on the palladium incorporated electrodes in a $50 \%$ ethanol $\mathrm{HCl}$ buffer solution $(\mathrm{pH}=1)$ : curve a, $2 \mathrm{a}\left(\mathrm{W}_{\mathrm{Pd}}=5.5\right.$ $\left.\mu \mathrm{g} \mathrm{cm}^{-2}\right)$; curve b, $2 \mathrm{~b}(8.5)$; curve c, P5HPy (9.3). $Q_{f}=0.14 \mathrm{C} \mathrm{cm}^{-2}$. Scan rate: $100 \mathrm{mV} \mathrm{s}^{-1}$. 
As shown in Fig. 2, when the currentpotential curves for the palladium incorporated film electrodes $\mathbf{2 a}$ and $\mathbf{2} \mathbf{b}$ in an ethanol aqueous solution were measured, cathodic currents based on hydrogen evolution were observed. The film electrode $2 \mathbf{a}$ and $\mathbf{2 b}$ gave large current at $c a-0.2$ and $-0.3 \mathrm{~V}$, respectively. In particular, the $2 \mathrm{a}$ is a good catalytic electrode because the hydrogen evolution current increases at lower potential in spite of small amounts of palladium (Fig. 2, curve a). However, a clear explanation to the behavior of the film electrode $\mathbf{2 a}$ could not be made. The cathodic current for the film electrode $\mathbf{2 a}$ and $\mathbf{2 b}$ increases linearly, while for P5HPy electrode containing much amount of palladium $\left(\mathrm{W}_{\mathrm{Pd}}=9.3\right.$ $\mu \mathrm{g} \mathrm{cm}^{-2}$ ), the suppression of current was observed in the latter half of potential sweep (Fig. 2, curve c). These results suggest that the migration of proton to palladium surface is enhanced by introduction of many hydroxyl groups in matrix.

For the film electrode $\mathbf{2 b}$ a constant current for hydrogen evolution was observed over 100 hours at $-0.4 \mathrm{~V}$ in an ethanol aqueous solution and the large current density was maintained at $c a$
$0.15 \mathrm{~mA} \mathrm{~cm}^{-2}$. This stability is probably due to strong interaction of hydroxyl group with the glassy carbon electrode surface. Further studies to find out optimum condition for the system of electrocatalytic hydrogenation using these film electrodes are now in progress.

This work was supported by Grant-in-Aid for Scientific Research on Priority Area (No.236) from the Ministry of Education, Science and Culture of Japan.

\section{RE'FERENCES}

1) F. Garnier, Angew. Chem. Int. Ed. Engl., 28, 513(1989); G. Tourillon and F. Garnier, $J$. Phys. Chem., 88, 5281 (1984); K. M. Kost, D. E. Bartak, B. Kazee and T. Kuwana, Anal. Chem., 60, 2379 (1988); G. Arai, K. Matsumoto, T. Murofushi and I. Yasumori, Bull. Chem. Soc. Jpn, 63, 121 (1990).

2) N. Takano, M. Nakabayasi and N. Takeno, Chem. Lett., 1995, 219.

3) S. Murahashi, T. Shimamura and I. Moritani, $J$. Chem. Soc., Chem. Commun., 1974, 931. 